\title{
Assessment of Occupational Exhaustion during the COVID 19 Period on Healthcare Professionals in the Rabat-Sale-Kenitra Region of Morocco
}

\author{
Kamar Tahiri ${ }^{1}$, Zakaria Abidli ${ }^{2}$, Abdeslam Amri $^{1}$, Abdelhamid Esserkassi ${ }^{3}$, Zineb \\ Hannoun ${ }^{1}$, Joumana El Turk ${ }^{2}$, Abdellatif Bour ${ }^{1}$ \\ ${ }^{1}$ Ibn tofail University, Faculty of Sciences of Kenitra, Laboratory of Biology and \\ Health, Morocco \\ ${ }^{2}$ International University of Casablanca, Faculty of Health Sciences, Morocco \\ ${ }^{3}$ Moulay Abdellah Salé Hospital, Ministry of Health, Morocco
}

Received: June 23, 2021. Revised: November 25, 2021. Accepted: December 13, 2021. Published: January 3, 2022.

\begin{abstract}
The novel Coronavirus 2019 (COVID-19) pandemic has resulted in an overall increase in new cases of depression and burnout and exacerbation of existing mental health problems, with particular emotional and physical harm to healthcare workers. For this reason, the aim of this study is to assess occupational exhaustion and to determine its risk factors within this population during the period of COVID- 19. This is about a cross-sectional study that was conducted from March to June 2020. The target population was health professionals working in the various departments of COVID-19, in public hospitals in Rabat-Sale-Kenitra region of Morocco. To evaluate the burnout, we chose the French version of the Maslach Burnout Inventory (MBI). The average age of the participants was $42.8 \pm 7.4$. The gender ratio was balanced at 1.1. Regarding professional status, $61 \%$ of the participants are nurses and $39 \%$ are doctors. The average professional seniority was $20 \pm 8.9$ years. As shown in the figure below, the MBI revealed that: $80 \%(n=72)$ suffered from burnout, of which $49 \%(n=44)$ had a low level, $17 \%$ $(n=15)$ had a moderate level and $14 \%(n=13)$ had a severe burnout. Unmarried status (Odds Ratio $=9.61 ; 95 \%$ IC $=$ [0.19-2.13]; P-value=0.001); The protective measures unavailable to health professionals (Odds Ratio= 7.13; 95\% IC=[2.32-21.89]; $P$-value=0.001); dissatisfaction with the efforts made by the Ministry of Health to fight Covid19 (Odds Ratio= 9.1; IC95\%=[2.82-29.37]; P-value=0.001) are the most important risk factors. In light of these results, interventions to support the mental well-being of health care professionals during and after the COVID-19 period should be implemented immediate.
\end{abstract}

Keywords-Burnout, COVID 19, Healthcare Professionals, Morocco.

\section{INTRODUCTION}

THE COVID 19 that hit the planet, in addition to the decimation of thousands of patients, and the confinement of entire populations, caused the overcrowding of public hospitals by massive influxes of patients suffering from serious forms of the desease [1]. The risks of such a pandemic Jon mental health are at least twofold: the psychological impact of confinement on general population, and on the vulnerable in particular, those suffering from mental disorders [2], and the impact on caregivers and in particular, those who are on the frontline. They have given the alert and some of them died from the disease, as LI WENLIANG [1], One of the first chinese doctors to alert on the dangerousness of the new corona virus; The caregivers have to face many difficulties, such as direct exposure to patients with high viral load, the increased risk of contamination, physical exhaustion, reorganisation of workspaces, adaptation to rigid work organizations, management of material shortage, the unusual high number of deaths among patients, colleagues or relatives,and ethical issues relating to therapeutic decision making ......

This epidemic highlighted the fragility of the psychological state of health workers during the epidemics [3]. Although studies have documented the state of mental health the risk fartors of psychological stress and the morbidity of health workers in previous desease pandemics [4], there are marked differences specific to the current situation. As a result, the psychological caracteristics of health workers during the COVID- 19 epidemic remain unknown [5].

In Morocco as far as we are aware, no scientific study has been 
carried out to determine the state of stress and occupational exhaustion of health care professionals in this sens, the aim of this study is to assess occupatinal exhaustion and to determine its risk factors within this population durig the period of COVID- 19.

\section{MATERIALS AND METHODS}

This is about a cross-sectional study that was conducted from March to June 2020. The target population was health professionals working in the various departments of COVID19, in public hospitals in Rabat-Sale-Kenitra region of Morocco. To achieve our goal, we have produced a survey form divided into four parts. The first part, consisting of a selfquestionnaire, focused on the participants' socio-demographic, professional and organizational information. The second consisted of a questionnaire to evaluate the hygiene measures level at the COVID-19 service, with two sub-dimensions: the hygiene measures made available to health professionals and the degree of satisfaction with the efforts made by the Ministry of Health to fight Covid-19. The third part evaluates the usual consumption of certain food supplements. Finally, to evaluate burnout we chose the French version of the Maslach Burnout Inventory (MBI), our population being French-Arabic speaking and the psychometric qualities of this version being satisfactory. It was presented in the form of a questionnaire consisting of 22 items, evaluating three dimensions: emotional exhaustion (EE), depersonalization (DP) and personal fulfillment (AP) [6-7-8-9-10-11]. A score was calculated and a rating in terms of degree of severity (low, moderated and high) was given for each of the dimensions, according to internationally accepted standards. The frequency of symptoms was measured by a scale of zero for the "never" response and six for the "every day" response. Burnout was considered low for a score below 18, moderate for a score higher than or equal to 18 , and high for a score above 30 . Depersonalization (PD) was considered as low for a score less than six, moderated for a score between six and 11, and high for a score higher than 12. Finally, the decrease of the sense of Personal Accomplishment (PA) was considered as moderate for a score between 34 and 39, and high for a score below 33 . The statistical methodology was based on two axes: descriptive statistics and analytical statistics. In the first component, the frequencies and characteristics of each variable studied were identified, which allowed us to give an overview of the participants. The results were expressed as percentages for the qualitative variables and as a mean \pm standard deviation for the quantitative variables. To determine the associations between the different studied variables, we used the $\chi^{2}$ test. The internal consistency of the three dimensions of the Maslach Burnout Inventory (MBI) was checked by using Cronbach's alpha coefficient. Acceptable values are normally expressed as a percentage of the mean and a mean \pm standard deviation of the standard deviation for the quantitative variables. The internal consistency of the three dimensions of the Maslach Burnout Inventory (MBI) was checked using Cronbach's alpha coefficient. Acceptable values are normally above 0.70 [12].

\section{RESULTS}

During the study period, we solicited 120 health professional records, 90 of which agreed to participate in this study $(75 \%)$. The average age of the participants was $42.8 \pm 7.4$ years, with a minimum age of 26 years and a maximum age of 60 years. The gender ratio was balanced at 1.1. For marital status, $60 \%$ were married, with $40 \%$ married with one child and $39 \%$ married with at least two children. Regarding professional status, $61 \%$ of the participants are nurses and $39 \%$ are doctors. The average professional seniority was $20 \pm 8.9$ years. In terms of addiction, we noted that $23 \%$ of the health professionals used tobacco with a sex ratio of smoking largely in favour of the male gender (Table 1).

Table 1. Socio-demographic and occupational distribution of the study population.

\begin{tabular}{|c|c|c|}
\hline Variables & Number & Percentage \\
\hline \multicolumn{3}{|l|}{ Gender } \\
\hline Female & 47 & $52 \%$ \\
\hline Male & 43 & $48 \%$ \\
\hline \multicolumn{3}{|l|}{ Marital status } \\
\hline Single & 11 & $12 \%$ \\
\hline Married & 63 & $70 \%$ \\
\hline Divorced & 16 & $18 \%$ \\
\hline \multicolumn{3}{|l|}{ Number of children } \\
\hline No children & 20 & $22 \%$ \\
\hline One child & 36 & $40 \%$ \\
\hline At least two children & 34 & $38 \%$ \\
\hline \multicolumn{3}{|l|}{ Professional status } \\
\hline Doctor & 35 & $39 \%$ \\
\hline Nurse & 55 & $61 \%$ \\
\hline \multicolumn{3}{|l|}{ Cigarette addiction } \\
\hline Yes & 21 & $39 \%$ \\
\hline No & 69 & $77 \%$ \\
\hline Mean age & \multicolumn{2}{|c|}{ 42.8 \pm 7.4 ans } \\
\hline $\begin{array}{l}\text { Mean professional } \\
\text { experience }\end{array}$ & \multicolumn{2}{|c|}{$20 \pm 8.9$ ans } \\
\hline
\end{tabular}

For a better reliability of the results, we calculated the Cronbach's alpha index for the whole questionnaire and for its different dimensions. Thus, the indices found are 0.74 for the questionnaire as a whole, 0.78 for emotional exhaustion, 0.81 for depersonalization and 0.91 for the feeling of personal accomplishment. These indices were satisfactory.

As shown in the figure below, the MBI revealed that: $80 \%$ $(\mathrm{n}=72)$ suffered from burnout, of which $49 \%(\mathrm{n}=44)$ had a low level, $17 \%(\mathrm{n}=15)$ had a moderate level and $14 \%(\mathrm{n}=13)$ had a severe burnout (Figure 1).Similarly, we found a highly significant difference between the presence or absence of burnout (Chi-square=32.40; $\mathrm{P}$-value $=0.001$ ). 


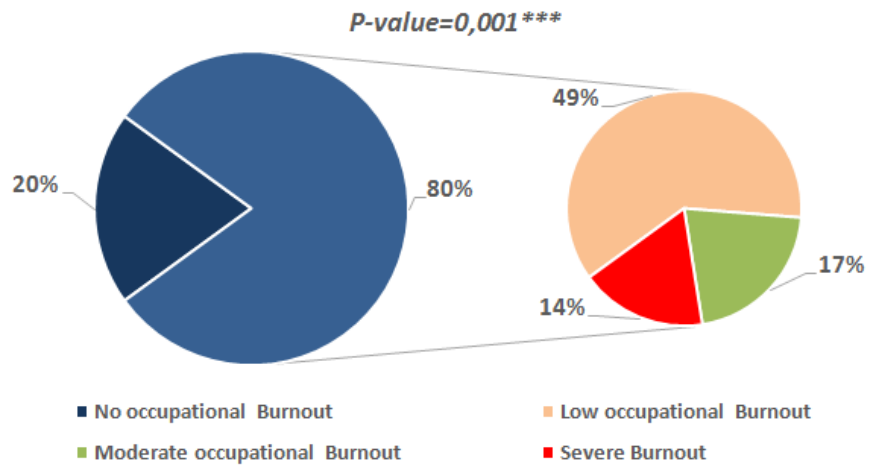

Figure 1. Profile of burnout among health professionals during the COVID-19 period.

Pathologically, we noted that $40 \%(\mathrm{n}=36)$ were emotionally exhausted, with an average of $(27.6 \pm 10.53) .41 \%(n=37)$ were

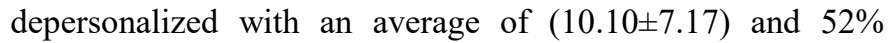
$(n=47)$ had a low level of personal achievement, with an average of (31.85 \pm 8.76$)$.

For the consumption of dietary supplements, we identified three main groups of the most consumed supplements, half of the participants opted for tonicity products, $35 \%$ used antistress supplements, mainly magnesium and calcium supplements, and $8 \%$ adopted the use of herbal moodregulating supplements.

In terms of hygiene measures available to participants to fight against Covid-19, we noted that $86 \%$ of participants declared the availability of FFP2 respiratory protective equipment (ARP). The totality of the participants declared the availability of single-use professional clothing with long sleeves, the prevention of a possible projection in the eyes by the systematic wearing of protective glasses, the wearing of a complete protection of the hair (charlotte, cap covering......) at the level of the sanitary structures. Similarly, $16 \%$ of the participants deplored the lack of hydroalcoholic solution in hospitals, and $40 \%$ of the health professionals subjectively declared their dissatisfaction with the protective measures available to them, with a highly significant differentiation between the three modalities (Chi-square $=9.86$; Pvalu $=0.001$ ).

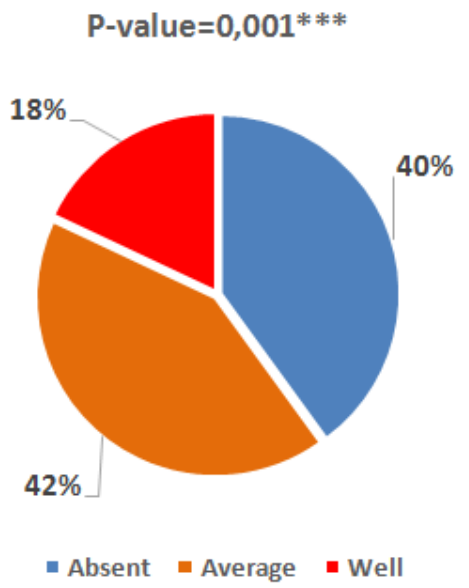

Figure 2. Distribution according to the degree of satisfaction with the protection measures made available.

Indeed, $69 \%$ of the participants are not satisfied with the efforts made by the Ministry of Health to fight against Covid19 with a highly significant differentiation between the two modalities (Chi-square $=30.46$; P-value=0.001).In order to highlight the factors that influence caregiver burnout during the COVID-19 period, we investigated the effects of factors such as : gender, employment status, number of children, addictions, use of dietary supplements, available protective measures, and participants' level of satisfaction with the Ministry of Health's efforts to address Covid-19 on caregiver burnout.

Table 2. Association between burnout and socio-demographic, occupational, organizational, and work-related risk factors among healthcare professionals during the COVID-19.

\begin{tabular}{|c|c|c|c|c|c|}
\hline \multirow[t]{2}{*}{ Variables } & \multicolumn{2}{|c|}{ Burnout } & \multirow[t]{2}{*}{ Odds-Ratio } & \multirow[t]{2}{*}{ IC95\% } & \multirow{2}{*}{$\begin{array}{c}\text { P- } \\
\text { value }\end{array}$} \\
\hline & Yes $(n=72)$ & No $(n=18)$ & & & \\
\hline \multicolumn{6}{|c|}{ Gender } \\
\hline Féminin & 39 & 8 & \multirow{2}{*}{0.64} & \multirow{2}{*}[0.19-2.13]{} & \multirow{2}{*}{$0.90^{\text {n.s }}$} \\
\hline Masculin & 38 & 5 & & & \\
\hline \multicolumn{6}{|c|}{ Marital Status } \\
\hline Unmarried & 26 & 1 & \multirow{2}{*}{9.61} & \multirow{2}{*}[0.19-2.13]{} & \multirow{2}{*}{$0.01 * *$} \\
\hline Married & 46 & 17 & & & \\
\hline \multicolumn{6}{|c|}{ Professional status } \\
\hline Doctor & 27 & 8 & \multirow{2}{*}{0.75} & \multirow{2}{*}[0.26-2.13]{} & \multirow{2}{*}{$0.50^{\text {n.s }}$} \\
\hline Nurse & 45 & 10 & & & \\
\hline
\end{tabular}




\begin{tabular}{|c|c|c|c|c|c|}
\hline \multicolumn{6}{|c|}{ Cigarette addiction } \\
\hline Oui & 18 & 3 & \multirow{2}{*}{2.69} & \multirow{2}{*}[0.56-12.88]{} & \multirow{2}{*}{$0.30^{\mathrm{n}}$} \\
\hline Non & 54 & 15 & & & \\
\hline \multicolumn{6}{|c|}{ Protective measures available to healthcare professionals } \\
\hline Not disponible & 59 & 7 & \multirow{2}{*}{7.13} & \multirow{2}{*}[2.32-21.89]{} & 0.001* \\
\hline Disponible & 13 & 11 & & & ** \\
\hline \multicolumn{6}{|c|}{ Level of satisfaction with the efforts of the Ministry of Health to fight Covid-19 } \\
\hline Not satisfied & 56 & 5 & \multirow{2}{*}{9.1} & \multirow{2}{*}{ [2.82-29.37] } & $0.001 *$ \\
\hline Satisfied & 16 & 13 & & & ** \\
\hline
\end{tabular}

N.S: Not significant; *: Significant at the 0.05 level (bilateral); ** Significant at the 0.01 level (bilateral); ***: Significant at the 0.001 level (bilateral); CI: Confidence Interval.

Unmarried status (Odds Ratio $=9.61 ; 95 \% \mathrm{IC}=[0.19-2.13] ; \mathrm{P}-$ value $=0.001)$; The protective measures unavailable to health professionals (Odds Ratio $=7.13$; 95\% $\mathrm{IC}=[2.32-21.89]$; Pvalue $=0.001$ ); dissatisfaction with the efforts made by the Ministry of Health to fight Covid-19 (Odds Ratio= 9.1; IC95\% $=[2.82-29.37]$; P-value $=0.001)$ are the most important risk factors.
In order to establish a relationship between the dependent variable expressed by the burnout and the independent variables that better predict this dependent variable, we used logistic regression.

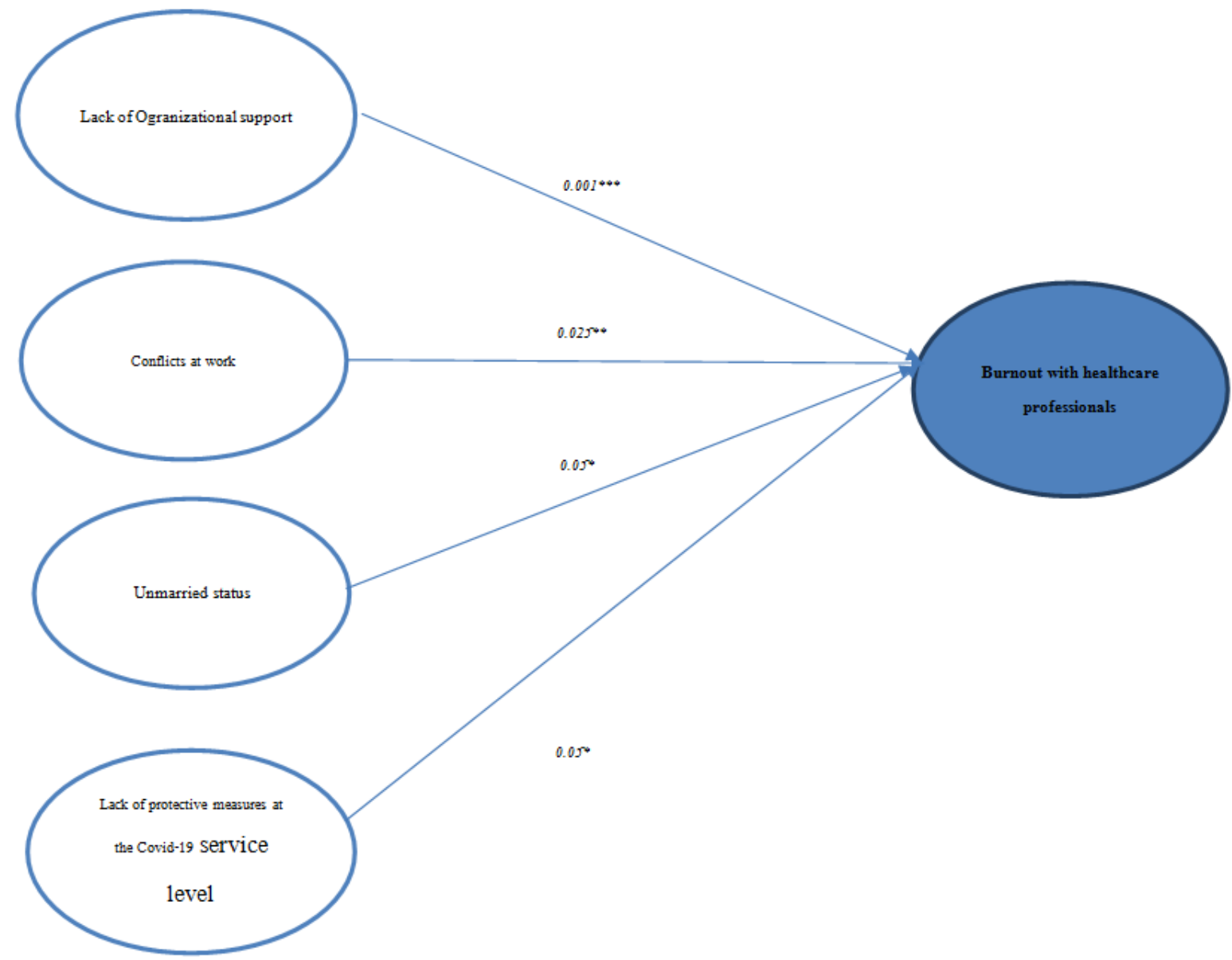

Figure 3. Logistic regression analysis of independent predictors of burnout among healthcare professionals in the Rabat-SaleKenitra region.

The results of this regression show that the psychological state of health professionals during the Covid-19 period could be explained by a large number of variables. These were 
grouped into three categories according to the degree of significance:

- The first category explains the Burnout in a way that very highly significant (less than 1 per thousand), it is : Lack of organizational support.

- The second category includes variables the probability of which significance is less than $1 \%$, it is: Conflicts at work

- The third category includes significant variables with a risk of less than $5 \%$, it is about : Marital status, Lack of protective measures at the Covid-19 service level.

\section{DISCUSSION}

Concern about the lack of material resources further alters their sense of safety among others. The relational environment is often new, due to external reinforcements or the creation of new teams, weakening or strengthening the sense of belonging. Communication between caregivers [13], the positioning of the management, of the supervisors are added to the anxietyproducing parameters. Fears abound: lack of skills, lack of resources to carry out one's work [14], making choices (or implementing them) in disagreement with personal ethical convictions. In addition, there is the need for a new private balance with the disruption of daily family life, and the feeling of permanent threat [15-16], with no way out, for oneself and those close to one's family. In our study, we noted that celibacy was a significant risk factor during the COVID-19 period.

In addition, the prevalence of burnout is not influenced by gender, as in other studies [17]. But the data are discordant: for Christina Maslach, men are more at risk than women [18]. Conversely, some studies [19] incriminate the female sex as being most at risk and suggest that this is due to their physical and psychological vulnerability, as well as greater emotionality towards the patients and the difficulty of reconciling work and family life [19].

The pandemic occurred in Morocco at a time when the public hospital was facing an unprecedented crisis due to a decline in material and human resources, wich is a source of anger and frustration. This already glaring lack of resources was revealed during the crisis. The lack of IPE and material (respirators, resuscitation beds) surpassed the worst scenarios ever envisaged with the rapid and massive influx of patients. Many caregivers felt helpless to care while protecting themselves, without any psychological support [15]. This dramatic situation generated a sense of helplessness unusual in its intensity. This is well demonstrated by our study. In addition to the lack of material and organizational resources, the absence of specific treatment of the infection favours the experience of powerlessness and personal inefficiency. The lack of understanding of the virus favours the experience of unpredictability which is difficult for any caregiver. The death of the patient can be perceived as a limitation of medical control, returning a feeling of personal powerlessness, and degrades the sense of usefulness of the caregiving function [20].
In terms of the prevalence of Burnout of health care professionals during this period of COVID-19, we found a burnout rate of $80 \%$. This rate in our population is much higher than the prevalence found in other studies [10-21-2223].

\section{CONCLUSIONS}

In light of these results, interventions to support the mental well-being of health care professionals during and after the COVID-19 period should be implemented immediately.

\section{References}

[1] El-Hage, W., Hingray, C., Lemogne, C., Yrondi, A., Brunault, P., Bienvenu, T., Etain, B., Paquet, C., Gohier, B., Bennabi, D., Birmes, P., Sauvaget, A., Fakra, E., Prieto, N., Bulteau, S., Vidailhet, P., Camus, V., Leboyer, M., Krebs, M. O., \& Aouizerate, B. (2020). Les professionnels de santé face à la pandémie de la maladie à coronavirus (COVID-19) : quels risques pour leur santé mentale ? [Health professionals facing the coronavirus disease 2019 (COVID-19) pandemic: What are the mental health risks?]. L'Encephale, 46(3S), S73-S80. https://doi.org/10.1016/j.encep.2020.04.00.

[2] Koh D., Lim M.K., Chia S.E. Risk perception and impact of Severe Acute Respiratory Syndrome (SARS) on work and personal lives of healthcare workers in Singapore: what can we learn? Med Care. 2005;43(7):676-682.

[3] Ho CS, Chee CY, Ho RC. Mental Health Strategies to Combat the Psychological Impact of COVID-19 Beyond Paranoia and Panic. Ann Acad Med Singap. 2020 Mar 16;49(3):155-160. PMID: 32200399.

[4] Sim K., Chong P.N., Chan Y.H., Soon W.S.W. Severe Acute Respiratory Syndrome-Related Psychiatric and Posttraumatic Morbidities and Coping Responses in Medical Staff Within a Primary Health Care Setting in Singapore. J Clin Psychiatry. 2004;65(8):1120-1127. doi: 10.4088/jcp.v65n0815.

[5] Cabarkapa, S., Nadjidai, S. E., Murgier, J., \& Ng, C. H. (2020). The psychological impact of COVID-19 and other viral epidemics on frontline healthcare workers and ways to address it: A rapid systematic review. Brain, behavior, \& immunity - health, 8, 100144. https://doi.org/10.1016/j.bbih.2020.100144

[6] Cathébras P, Begon A, Laporte S at al. Professional exhaustion among general practitioners. Press Med. 2004; 33:1569-1574.

[7] Maslach C, Jackson SE, Leiter MP. The Maslach Burn out Inventory, $3^{\circ}$ ed. Consulting PsychologistsPress, Palo Alto 1996.

[8] Dion G, Tessier R. Validation of the translation of Maslach and Jackson's burnout inventory. Can J BehavSci 1994; 26: 210-27

[9] Canoui P, Mauranges A. Caregiver burnout syndrome. Masson; Paris 2001. 
[10]El Kettani A, Serhier Z, Bennani Othmani M at al. The evaluation of Burnout syndrome among doctors in training at the Ibn Rochd University Hospital in Casablanca. The Pan African Medical Journal. 2017; 27:243.

[11] Abdeslam Amri, Zakaria Abidli, Mohamed Elhamzaoui, Mounir Bouzaboul, Ziri Rabea, Ahmed Omar Touhami Ahami. Assessment of burnout among primary teachers in confinement during the COVID-19 period in Morocco: case of the Kenitra. The Pan African Medical Journal. 2020; 35 (2): 92.25.

[12] Cronbach LJ. Coefficient alpha and the internal structure oftests. Psychometrika 1951;16(3):297-334.

[13]Lee S.H., Juang Y.Y., Su Y.J. psychological impacts on SARS team nurses and psychiatric services in a Taiwan general hospital. Gen Hosp Psychiatry. 2005;27(5):352358 .

[14] Greenberg N., Docherty M., Gnanapragasam S. Managing mental health challenges faced by healthcare workers during covid-19 pandemic. BMJ. 2020;368:m1211

[15] Chen Q., Liang M., Li Y. Mental health care for medical staff in China during the COVID-19 outbreak. Lancet Psychiatry. 2020;7(4):e15-e16.

[16] Koh D., Lim M.K., Chia S.E. Risk perception and impact of Severe Acute Respiratory Syndrome (SARS) on work and personal lives of healthcare workers in Singapore: what can we learn? Med Care. 2005;43(7):676-682.

[17] Faille A. Etude descriptive de la population des médecins généralistes libéraux du Nord-Pas-de-Calais et prévalence du Burn Out: réalisée à partir de l'envoi de 1000 questionnaires (Doctoral dissertation, Thèse d'exercice, Université du droit et de la santé, Lille, France. 2012.

[18] Schraub S, Marx E. Le point sur le syndrome d'épuisement professionnel des soignants ou burn out, en cancérologie. Bulletin du cancer. 2004 Sep 1;91(9):673-6.

[19] Hyman SA, Michaels DR, Berry JM, Schildcrout JS, Mercaldo ND, Weinger MB. Risk of burnout in perioperative clinicians: a survey study and literature review. Anesthesiology. 2011;114(1):194- 204.

[20] Chahraoui K., Bioy A., Cras E. Vécu psychologique des soignants en réanimation : une étude exploratoire et qualitative. Ann Fr Anesth Reanim. 2011;30(4):342-348.

[21]Zeter C. Burnout, conditions de travail et reconversion professionnelle chez les médecins généralistes de la région Poitou-Charentes. Thèse d'exercice, Poitiers. 2004.

[22] Rakotondrainibe A, Randriamizao HMR, Ratsimbazafy NS, et al. Burnout syndrome et ses facteurs chez les médecins de deux centres Hospitalo-Universitaires d'Antananarivo [Burnout syndrome and associated factors among physicians in two University Hospitals in Antananarivo]. Pan Afr Med J. 2018;31:63. Published 2018 Sep 27. doi:10.11604/pamj.2018.31.63.11123.

[23] Grau A, Suner R, Garcia MM. Burn out syndrome in health workers and relationship with personal and environmental factors. GacSanit 2005;19:463-70.

\section{Creative Commons Attribution License $\mathbf{4 . 0}$} (Attribution 4.0 International, CC BY 4.0)

This article is published under the terms of the Creative Commons Attribution License 4.0 https://creativecommons.org/licenses/by/4.0/deed.en_US 